\title{
Ride-on lawnmowers warnings: Slope measurements and safety-by-separation
}

\author{
Edward W. Karnes ${ }^{\mathrm{a}}, \mathrm{S}$. David Leonard ${ }^{\mathrm{b}}$, David R. Lenorovitz ${ }^{\mathrm{c}}$ \\ ${ }^{a}$ Edward W Karnes, LLC., 5843 S. Willowbrook Drive, Morrison, CO 80465 USA \\ ${ }^{b}$ S. David Leonard, Department of Psychology, University of Georgia, Athens, GA 30602, USA \\ ${ }^{c}$ David R. Lenorovitz, LENPRO Services, Inc. Denver, Colorado, USA.
}

\begin{abstract}
Various single-rider open vehicles, such as lawnmowers, are susceptible to overturning on slopes that are too steep for them. Warnings have included separation from the vehicles and avoiding slopes that are too steep. A recommended maximum slope is commonly 15 degrees. However, many individuals cannot evaluate slopes just by sight. Some mower manufacturers have warned about too steep slopes and have provided slope gauges for users to determine the slopes in natural settings. This article evaluated the usefulness of such gauges for users who might be expected to need to evaluate slopes and the efficacy of a separation procedure for avoiding injuries. It was concluded that neither of these were likely to be successful and suggestions are made for alternative approaches.
\end{abstract}

\section{Introduction}

Injuries and deaths involved in the use of riding lawnmowers have been a major safety concern for several decades, as they became commonplace beinning in the late 1970s. The Consumer Product Safety Commission (CPSC) has conducted numerous studies addressing hazard patterns associated with the use of consumer walk-behind, lawn tractor, and zero-turn-radius (ZTR) lawnmowers as well as the most common riding mowers. Various hazard patterns were identified and vehicle overturns of riding mowers creating fatal and non-fatal injuries were identified as a major safety concern by the CPSC. In addition, the Occupational Safery and Health Administration (OSHA) addressed safety concerns regarding overturns of commercial riding mowers.

The CPSC reported that riding mower instability was a hazard pattern associated with $2200(13 \%)$ of a total of 17,000 injuries and with $440(20 \%)$ of 1,916 hospitalizations in the four-year sample from 1987 through 1990 [1]. The analysis concluded that the ride-on mower annual injury rate was more than three times higher than the annual rate for walk-behind mowers, and in $75 \%$ of the overturns the mower landed on top of the operator. In 2003, the CPSC estimated the annual number of injuries related to ride-on lawnmowers at 35,922 , and during the six month period from
April 1, 2003 to August 31, 2003, CPSC estimated 8000 injuries from overturn hazards [2]. David [3] reported that between January 1, 1987 and December 31, 1990, 362 deaths associated with power ride-on mowers were reported to the CPSC. Most injuries were a function of the weight of the mower as it came down on the operator. Melvin Meyers [6] provided a comprehensive discussion of the hazards of consumer and commercial riding mower turnovers and the need for rollover protection systems (ROPS) and seat belts as standard equipment on all riding mowers.

Slope steepness is a major hazard factor for both rear overturns (longitudinal) and side overturns (lateral) and most manufacturers of riding lawnmowers provide on-product and owner's manuals warnings that the lawnmowers should never be used on slopes in excess of $15^{\circ}$ (a rise of approximately $2 \frac{1}{2}$ feet every 10 feet). The warnings advise that a riding mower could overturn causing serious injury or death. In a study examining judgments of slope steepness and the likelihood of tip-over's of machines on slopes [5] we reported that: (a) there was a great deal of variability in perceptions of rollover risks for various slopes; and (b) the mean slope angle at which the most conservative estimators indicated a beginning of concern of a tipover while riding on the slope was $16.2^{\circ}$ and for the least conservative estimators it was $24.4^{\circ}$. The 1996 study concluded that information regarding the risk of rollovers on 
slopes needed to be provided in a form that will be received and acted upon by users who would be at risk when operating these types of machines on naturally occurring slopes.

To assist consumers in measuring the degrees of slope, most manufacturers of riding lawnmowers have provided a slope gauge (shown in Figure 1) in the owner's manuals for the lawnmowers. In some legal cases involving injuries sustained in overturns of riding mowers, the operators using the slope gauge underestimated the degrees of slope and experienced longitudinal and/or lateral rollovers. Manufacturers of the lawnmowers testified that the slope gauge can provide an accurate measurement of the steepness of a of the slope gauge. Therefore, we conducted a study to assess the accuracy of slope measurements using the slope gauge which is displayed in Figure 1

\section{Method}

\subsection{Participants}

Twelve adult male employees of a private golf course located in Denver, Colorado volunteered as participants to measure the degrees of slope for each of the three slopes using the slope gauge.

\section{USE THIS PAGE AS A GUIDE TO DETERMINE SLOPES WHERE YOU MAY NOT OPERATE SAFELY.}

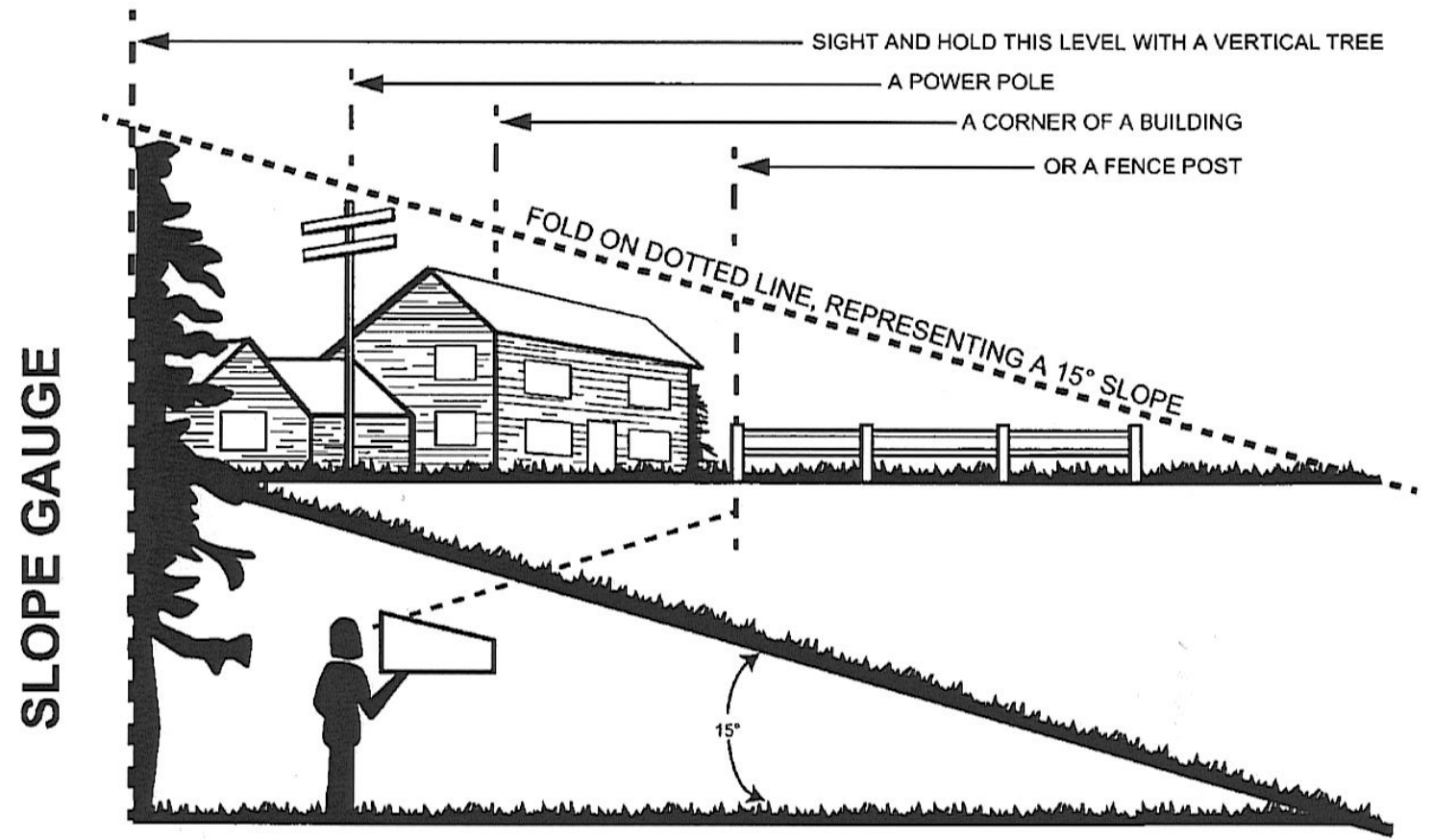

WARNING

Do not mow on inclines with a slope in excess of 15 degrees (a rise of approximately 2-1/2 feet every 10 feet). A riding mower could overturn and cause serious injury. If operating a walk-behind mower on such a slope, it is extremely difficult to maintain your footing and you could slip, resulting in serious injury.

Operate ZERO-TURN mowers across the face of slopes, never up and down slopes.

Operate WALK-BEHIND mowers across the face of slopes, never up and down slopes.

Figure 1. Mowing "Slope Gauge" - contained in Cub Cadet Z-Force 50 Operator's and Service Manual.

slope within a degree or so, and that, by using the slope gauge, it is easy for operators to determine whether a slope can be safely mowed. In an effort to determine the reliability and accuracy in using the slope gauge, we surveyed the literature and found no empirical study directed at measuring the accuracy of use

\subsection{Procedure}

The golf course provided a variety of slopes of various steepnesses. We selected three very distinctive grassy slopes, and using a digital inclinometer measured, the degrees of slope of each of the sites. Each slope was 
measured four times at slightly different locations on the slope. The three sites provided average slope measurements of $21^{\circ}$, $22^{\circ}$, and $28^{\circ}$. Participants were run individually. Prior to being taken to the first slope to be measured, each participant was asked if they were familiar with measurements in degrees of slope; all 12 indicated that they were. The order of slopes to be measured was counterbalanced across participants. slopes the mean overestimate equaled $11.5^{\circ}$ and the largest average overestimate was $13.33^{\circ}$. The frequencies of 10 versus 2 produced, $\chi=5.34, p=.021$ indicating the tendency to underestimate was reliable.

The results indicated that individuals using the slope gauge to measure steepness of slopes to be mowed could result in underestimations and for some users, significant and potentially dangerous underestimations.

Table 1

Summary of results of observations

\begin{tabular}{|l|l|l|l|}
\hline & Slope 21 & Slope 22 & Slope 28 \\
\hline Mean & & & \\
\hline Variance & 17.33 & 22.25 & 23.00 \\
\hline Winsorized mean & 24.61 & 165.48 & 41.00 \\
\hline Winsorized variance & 15.75 & 18.50 & 21.58 \\
\hline
\end{tabular}

Participants were presented with a slope gauge and they were required to examine and read the slope gauge before going to the first site. They were asked if they had any questions regarding use of the gauge. If they did, a demonstration of how to use the gauge was provided.

\section{Results}

The results are summarized in Table 1 . Separate single mean $t$ tests were performed for the responses made at each of the three slopes using the Winsorized mean and variance approach to hypothesis testing [4]. Using the Winsorized means for the three slopes, the test subjects reliably underestimated the actual degrees of slope by an average of $5.03^{\circ}$. For the $21^{\circ}$ slope, the under estimate was $5.25^{\circ}, t(11)=22.32$, $p<.0005$; for the $22^{\circ}$ slope the mean under estimate was $3.43^{\circ}, \mathrm{t}(11)=2.26, \mathrm{p}=.0451$; and for the $28^{\circ}$ slope it was $6.42^{\circ}, \mathrm{t}(11)=7.05$, $\mathrm{p}<.0005$ ).

The average under- or over-estimates across the three sites for each of the 12 participants were computed. Ten participants produced average underestimates and two subjects produced average overestimates. The mean underestimate equaled $6.23^{\circ}$. The largest average underestimate was $9.33^{\circ}$. For the two participants who over estimated the

\section{Separation assumption}

Another human factors issue involved in rollovers of riding lawnmowers is the concept of safety by separation. Manufacturers of riding lawnmowers that are provided without rollover protection systems (ROPS) have testified that a reason for not providing ROPS is that the protection system would make the mower more dangerous in the event of a tip over or rollover because operators are safer and less likely to be injured by simply jumping off of the machine in a tip over or rollover event. The contention that operators are safer without ROPS and sustain fewer injuries by jumping off of the vehicle is known as safetyby-separation. That concept has a long history in the safety literature and has been frequently addressed in discussions of rider safety when operating various motorized vehicles.

In numerous engineering and human factors investigations of injuries sustained by operators of motorized recreational vehicles involved in longitudinal, rearward flipovers, we have found that a typical rearward overturn occurs very suddenly, in two seconds or less, and without warning. Studies of rear rollovers of farm tractors have shown that the rear rollovers are particularly dangerous because they happen so quickly, giving operators little time to react. Research on overturns of tractors has shown that "it takes only 0.75 seconds to reach the critical point of no return where the center of gravity moves over the rear axle and 
outside the base of stability. "From the time the tractor begins to roll over, the incident can take as little as 1.5 seconds" [7]. Given that vehicle rearward rollover times may be two seconds or less, the ability of a rider to successfully separate from a vehicle in a rearward rollover is at best questionable. Indeed, a significant amount of time would be taken in deciding which way to go.

Given a manufacturer's decision not to provide any form of operator protection and a contention that rider safety is best achieved by jumping off of the vehicle in an overturn event, it is our opinion that, at a minimum, warnings regarding that safety issue should be provided on-product and in the owner's manual for the vehicles. Safety-by-separation warnings could at least alert a riding mower user to the need to be able quickly to separate from an overturning mower and perhaps reduce the reaction time for the separation responses. It is likely that without some discussion of the possible necessity for such an action, operators might also not consider or recognize the difficulty of performing such a maneuver. In a survey of owners manuals provided by manufacturers of riding lawnmowers that do not provide ROPS, no warnings regarding that issue was found. While specific instructions regarding separation may be difficult to provide given the myriad ways in which overturns can occur, the failures to provide safety-by-separation warnings or instructions regarding jumping off of the vehicle in event of a rollover is troubling.

\section{Discussion}

The problem of accidental deaths and injuries from tipovers and rollovers has been known for some years. If users could accurately evaluate the amount of slope of a particular terrain, they might avoid dangerous areas, but even with the aid of a slope gauge it is likely they would misjudge the amount of slope. A relatively simple device might be used to warn users of a slope that is too great for safe operation. It could be mechanical or electronic, and would be designed to emit an auditory signal at a slope of 15 degrees. It would be possible to increase the intensity or some other aspect of the signal as the slope increased. Conceivably an engine shutoff could be produced at a particular level. A problem with such an approach is that stopping the engine at some points could increase the probability of a tip over or rollover, and careful research would need to be performed to evaluate such an eventuality. But the usefulness of such a device in reducing injuries and deaths and the concomitant costs to the manufacturer would be worth it.

\section{References}

[1] Adler, P. (1993). Ride-on Mower hazard analysis (1987-1990). Washington, D.C. Consumer Product Safety Commission, Directorate for Epidemiology Hazard Analysis Division.

[2] Adler,P. \& Schroeder,T. (2004). Hazard analysis of power lawn mower studies calendar years 2003 and 1993. Washington, D.C. Consumer Product Safety Commission, Directorate for Epidemiology Hazard Analysis Division.

[3] David J.A. (1993). Deaths Related to Ride-on Mowers 1987-1990. U. S. Consumer Product Safety Commission, Washington, DC 20207, Directorate for Epidemiology Hazard Analysis Division.

[4] Keselman, H., Algina, J., Lix,L., Wilcox, R., \& Deerig, K., (2008). A generally robust approach for testing hypotheses and setting confidence and rules for effect sizes. Psychological Method, 13, $110-$ 129.

[5] Leonard S.D. \& Karnes, E.W. (1996). Factors influencing judgements of the likelihood of tipovers of machines on slopes. Advances in Industrial Ergonomics and Safety. Taylor and Francis, 1996, 723-728.

[6] Meyers, M. L. (2009). Ride-on lawnmowers: The hazards of overturning. Professional Safety. American Society of Safety Engineers.

[7] Smith, D.W. (2005). Safe Tractor Operation: Rollover Protection. Extension Safety Program, The Texas A\&M Universuty Systeem, April, 2005. 